\title{
Pengembangan Wawasan Islam Kebangsaan Mahasiswa Melalui Konseling Sebaya di Masjid Kampus
}

\author{
Lukman Fauroni $^{1}$, M. Rusydi ${ }^{2 *}$, Maftukhatusolikhah ${ }^{3}$, Nur Mukhlis Zakaria ${ }^{4}$ \\ ${ }^{1}$ IAIN Surakarta, ${ }^{2,3}$ UIN Raden Fatah, ${ }^{4}$ UIN Sunan Ampel \\ *Penulis Koresponden: mrusydi_uin@radenfatah.ac.id
}

\begin{abstract}
Abstrak
Radikalisme bisa merasuk di semua agama, perbedaannya hanya terletak pada model ekspresi dan intensitasnya. Gejalanya dalam ranah kehidupan keagamaan mahasiswa mulai terungkap. Dalam konteks agama Islam, peran serta masjid kampus dituntut agar berdampak signifikan dalam mengurai permasalahan relasi agama dan bangsa yang keras dengan penciptaan budaya akademik yang damai. Melalui kajian literature, masjid dapat menjadi fasilitator bagi jamaah mahasiswa untuk terlibat langsung dalam mengatasi permasalahan teman sebaya khususnya dalam meningkatkan Islam berkebangsaan yang anti kekerasan.
\end{abstract}

Kata kunci: masjid kampus, radikalisme, Islam kebangsaan, tutor sebaya

\begin{abstract}
:
Radicalism can pervade in all religions, the only difference lies in the model of expression and intensity. Symptoms in the realm of student religious life are beginning to be revealed. In the context of Islam, the participation of university mosques will have a significant impact in solving the problems of religious and national relations with the creation of a peaceful academic culture. Through literature studies, mosques can become facilitators for student congregations to be directly involved in overcoming peer problems, especially in promoting an anti-violence national Islam.
\end{abstract}

Keywords: higher education, mosques, Radicalism, national Islam, peer counselors

\section{Pendahuluan}

Masjid kampus telah menjadi pusat keagamaan Islam baik di universitas, instititut, sekolah tinggi dan bentuk perguruan tingga lainnya di Indonesia. Peran sangat strategis karena tidak terbatas pada pelaksanaan ibadah salat berjamaah semata, namun juga menjadi ajang bagi peningkatan Bagi sivitas akademika dan mahasiswa muslim. Masjid menjadi alternative bagi diskusi dan perdebatan mendalam dalam penguasaan akademik selain pendalaman iman dan Islam. Bagi masyarakat, pusat peribadatan Islam itu 
bukanlah ruang yang eksklusif namun terbuka bagi siapa saja menuju kebaikan dalam berbagai dimensi kehiduapan manusia yang dirida oleh-Nya (Imroatun 2015).

Dewasa ini. Masjid tidak sebatas tempat belajar al Quran bagi usia dewasa seperti mahasiswa dan dosen (Rahayu et al. 2019) atau singgah guna pennunaian salat lima waktu. Suasana keterbukaan dalam aktivitas masjid telah melahirkan poros baru yang bisa mengangkat syiar Islam berkebangsaan di Indonesia dalam kancah kehidupan kenegaraan Indonesia hingga menjadi embrio Partai Kesejahteraan Sosial (Atika, Sunaryanto, dan Widiono 2016; Rahmat 2011). Kebaikan itu ternyata telah diiringi gejala negatif yang semakin menyeruak dalam masyarakat akibat munculnya radikalisme dalam perguruan tinggi. Riank-riak kecil telah menjadi gelombang itu harus diwaspadai karena dampak terhadap kekerasan dalam kehidupan masyarakat semakin jelas. Dalam ruang yang sama, sebagian halaqah dalam MK telah berjalan di luar batas-batas wajah damai yang penuh rahmat dari agama Islam. Peperangan ideologi melalui pendekatan gazw al-fikr telah menjadi bahan kajian yang melewati batasan yang seharusnya. Literature yang menjadi rujukan pun semakin mengarahkan kepada ajaran Islam transnasional tanpa mengindahkan bagaimana kehidupan masyarakat yang heterogen seperti NKRI. Pemikiran para Islamis di era awal modern yang mendambakan kemerdekaan dan kebebasan bagi seluruh umat Islam tanpa batas territorial negara menjadi rujukan pokok dari pertemuan-pertemuan keagamaan mahasiswa (Hasan 2018).

Situasi dilematis dalam PT ini bahkan telah menjadi perhatian serius dari Badan Intelejen Negara (BIN) bahwa sivitas akademika, khususnya mahasiswa, karena dikategorikan telah terpapar dengan faham radikal yang membolehkan kekerasan dalam menyelesaikan permasalahan (Siregar 2018). Temuan penelitian Balitbang kemenag RI tentang faham keagamaan radikal di lingkungan kemahasiswaan PTKI telah menyimpulkan hal yang sama. Kondisi tidak berbeda juga telah ditemukan di PTU (Basri dan Dwiningrum 2018; Huda, Haryanto, dan Haryanto 2018) 
Permasalahan radikalisme dalam keyakinan sesungguhnya bukanlah semata dialami pada dakwah Islam di masjid kampus Indonesia. Semua mahasiswa lintas agama di dunia berpengalaman dengan hal yang sama meski berbeda dalam bentuk pengekspresian serta tingkat intensitas. Meski demikian mahasiswa yang menganut agama samawi dari Timur Tengah berpotensi untuk bersikap dan bertindak kekerasan dari pada mereka yang agamanya tersebar pertama kali dari India (Hasan 2018).

Penguatan masjid PT sebagai pusat agama dalam penyebaran nilai dan moral Islam kebangsaan yang damai kemudian menjadi penting dan strategis (Alfin dan Santoso 2013). Wajah Masjid sebagai pusat kegiatan bagi pemberdayaan umat di seluruh bidang kehidupan termasuk hubb al-watan harus dipoles semakin nyata sesuai zaman. Masjid bersama pesantren dan madrasah tidak bisa melepaskan diri dari peran sejarah nasional Indonesia yang selalu berdekatan dengan persoalan kebangsaan (Imroatun 2016)

Pengembangan masjid sebagai pusat agama bertujuan bagi penciptaan budaya masyarakat Indonesia yang damai penuh kedinamisan. Jamaah mahasiswa sebagai pengunjung utamanya bisa terlibat langsung daengan saling membantu untuk mengatasi permasalahan teman sebaya khususnya dalam meningkatkan Islam berkebangsaan yang anti kekerasan. Pendidikan kemandirian kemudian tidak hanya tersampaikan di sekolah dasar (Prastomo et al. 2019), namun telah bervariasi hingga pendidikan tinggi.

Peran besar masjid kampus semakin terasa apabila dipandang dari kapasitasnya sebagai unsur dalam Sistem Pendidikan Nasional PT. pertanggungjawaban bagi PT dan PTKI diletakkan pada kemampuan dalam mengeluarkan lulusan yang terampil berkemampuan untuk memecahkan persoalan manusia secara nasional hingga global. Didalamnya ada beban tersemat untuk terlibat aktif dalam pencerdasan tata kehidupan berbangsa Indonesia, dengan perwujudan masyarakat tamaddun yang berkemandirian, berkesejahteraan, sehingga berkesiapan tinggi dalam persaingan.

\section{Metode}

Penelitian pendahuluan ini mengandalkan studi literatur secara kualitatif. Hal demikian dimaksudkan untuk pendalaman pengetahuan masjid 
kampus sebagai pusat penyebaran Islam berkebangsan di Indonesia termasuk sejumlah penelitian yang berkaitan secara sintesis. Cara demikian bisa merangkum berbagai sumber penting guna memperjelas peta perkembangan peran masjid kampus. Upaya melalui pendekatan analisis muatan guna merumuskan tawaran sebuah strategi penting menguatkan peran masjid kampus dengan mengoptimalkan mahasiswa dalam permasalahan agama kebangsaan dari teman sebayanya berdasarkan runtutan sejarah Islam dan kemasjidan di perguruan tinggi Indonesia.

\section{Masjid Kampus Sebagai Pusat Agama Berkebangsaan}

Pada semua agama pasti terdapat kelompok dan sekte yang berpola radikal dalam beragama. Voll (1994) menduga kemunculan para kaum radikal fundamentalis yang militan itu mulai muncul di awal tahun 1990an, baik dari agama Hindu di Srilangka, maupun Yahudi di Israel hingga pergerakan agama lain di berbagai kawasan dunia. Pengertian radikal dalam beragama berspesifikasi tersendiri. Qardawi menyebutnya sebagai bentuk penerapan agama yang tidak seharusnya sehingga berada di posisi yang memberatkan atau berlebih-lebihan. Pribadi dan kelompok dalam kriteria radikal adalah biasanya sering hanya mengakui satu kebenaran dengan mengingkari pihak yang tidak berada dalam pikiran yang sama. Kesukaannya menaikkan atau melebihkan hokum dari yang sepantasnya, misalnya, ketentuan sunnah namun dinyatakan wajib atau makruh berubah haram. Mereka juga selalu berlebihan dalam bersikap dan bertindak sehingga tidak menyesuaikan dengan tempatnya. Pola interaksi dan komunikasi sosial samasama bersikapa memaksa sehingga cenderung keras dan emosional; persangkaan buruk selalu muncul dari dalam hati saat berhubungan dengan dari luar kelompok; perbedaan pendapat di daklangan mereka tidak bisa diterima sehingga klaim pengkafiran biasa terjadi.

Kelemahan dari sikap berlebihan yang tidak lazim itu setidaknya antara lain: menjadi pribadi atau keompok yang tidak disuka karena tabiatnya melebihi kelaziman; Gagasannya hanya berlaku temporer sehingga belum bisa bertahan sepanjang usia; dan sikap dan tindakan mereka selalu atau mendekati pelanggaran atas hak orang lain (Qardawi 2001). Huda et al. ( 
2018) menengarai kehidupan sosial penganut agama secara radikal cenderung memisahkan diri dengan bersikap enggan berinteraksi dengan orang lain yang pemikirannya tidak sejalan bahkan menganggap wajar untuk bertindak keras (violence) karena diasumsikan telah berbuat sewenang-wenang terhadap diri, kelompok, atau keyakinannya.

Sebab paling menonjol dari kemunculan kaum radikal adalah interpretasi dari Kitab Suci masing-masing agama yang bertekanan pada makna tesktual daripada pengiringan dengan pemahaman alasan historis yang melatari penurunannya. Dalam prinsip dasar, semua agama memiliki kesamaan dalam mengutamakan jalan damai penyelesaian permasalahan hidup manusia. Islam diturunkan untuk menjadi rahmah bagi seluruh alam tertulis dalam al-Anbiya (21): 107 (Kemenag RI 2010) adalah contohnya.

Dalam penafsiran isi al-Quran (Kemenag RI 2010), kitab suci orang Islam, terdapat juga beberapa ayat yang dapat ditafsirkan secara tekstual tanpa pertimbangan historisitas asbab an-nuzul dari ayat tersebut (Rodin 2016). "Hai orang-orang beriman, perangilah orang-orang kafir yang ada di sekitar kamu dan hendaklah mereka merasakan kekerasan darimu ..." (at-Taubah (9):123); “... dan janganlah rasa belas kasihan kepada keduanya mencegah kamu untuk menjalankan agama Allah, jika kamu beriman kepada Allah" QS Al-Nur (24) : 2. "Sesungguhnya orang Mukmin adalah mereka yang beriman kepada Allah dan Rasul-Nya, kemudian mereka tidak ragu-ragu dan berjihad (berjuang) dengan harta dan jiwa mereka di jalan Allah, mereka itulah orangorang yang benar" QS Al Hujurat (49): 15. "Hendaklah ada diantara kalian ada segolongan orang yang mau mengajak kepada kebaikan, menyuruh orang berbuat benar dan melarang perbuatan mungkar. Mereka itulah orang-orang yang beruntung" QS Al Maidah (5): 104.

Dalam kitab Injil pun banyak ayat-ayat yang bisa disalahtafsirkan sebagai pendukung kekerasan bila tidak dipahami dalam konteks apa ayat itu diturunkan. Sebagai contoh, dalam Al-Kitab Perjanjian Baru ada ayat-ayat yang berkaitan dengan Jesus;

"Jangan anggap Aku datang membawa damai ke bumi ini. Aku tidak datang membawa damai. Aku datang membawa pedang (Matius 10-34). Tujuan-Ku datang adalah membuat hal ini 
terjadi, 'Orang-orang dalam suatu keluarga akan saling bermusuhan. Anak laki-laki akan melawan ayahnya. Anak perempuan akan melawan ibunya. Menantu perempuan akan melawan ibu mertuanya. "Sekarang di mana musuh-musuhku? Di mana orang yang tidak menginginkan aku menjadi raja? Bawa musuh-musuhku kemari dan bunuh mereka di depanku Lukas 19:27.

Perjanjian Lama juga berisi gambaran tentang kekerasaan: "Tetapi jikalau barang seorang telah membunuh temannya dengan sengaja, niatnya hendak membunuh dia juga, maka, patutlah kamu mengambil orang itu, jikalau dari hadapan mezbah-Ku sekalipun, supaya ia mati dibunuh" (Kejadian 21: 14). "Barangsiapa yang sudah memalu bapanya atau ibunya, ia itu tak dapat tiada mati dibunuh juga" (Kejadian 21:15). "Barangsiapa yang mencuri orang, entah sudah dijualnya, entah orang itu terdapat lagi dalam tangannya, ia itu takkan jangan mati dibunuh juga" (Kejadian 21:16). "Dan lagi barangsiapa yang mengutuki bapanya atau ibunya, ia itu tak akan jangan dibunuh juga hukumnya" (Kejadian 21:17). "Maka diikutnya orang Israel itu dari belakang sampai ke dalam petidurannya, lalu ditikamnya keduanya, baik orang Israel, baik perempuan itu tengah ia berkehendak, maka, seketika itu berhentilah bala itu dari pada bani Israel" (Kejadian 25:8). "Maka jumlah segala orang yang mati sebab kena bala itu dua puluh empat ribu banyaknya" (Kejadian 25:9). "Sebab itu bunuhlah segala yang laki-laki di antara anakanak itu dan bunuhlah segala perempuan yang sudah tahu bersetubuh dengan orang laki-laki" Kejadian 31:17.

Perkembangan penfasiran demikian bisa menjadi perhatian dari masing lembaga peribadatannya. Cerminan sejarah awal dari keberadaan masjid di awal kebangkitan Islam bisa menjadi pokok acuan. Masjid merupakan wujud dari ketakwaan umat. Tingkat pecapaian tertinggi itu merangkum dimensi iman, islam dan ihsan dalam satu kesatuan. Komprehensifitas itu sudah terlihat sejak awal kebangkitan Islam di zaman Rasulullullah. Selain ibah salat limat waktu berjamaah, masjid telah digunakan sebagai wahana, sosial pendidikan, pemeberdayaan ekonomi para ahli sufi politik kemusyawaratan hingga administrasi kenegaraan. Rasulullah juga mengajak semua orang ke masjid dari segala umur dan jenis kelamin. Usia dewasa bisa memanfaatkannya untuk belajar al-Quran dengan 
bimbingan langsung dari Nabi selain menjadikan mereka bertukar pikiran untuk berusaha ekonomi kesejahteraan. Para muslimah berhak sama dengan muslim wanita sembari meningktkan ketrampilan menenun dan memintal. Usia anak dan remaja tak terkecuali, dengan belajar di serambi dan luar masjid sehingga berkesempatan mengasah ketrampilan berkuda, pemanahan ataupun renang yang menjadi minat masing-masing. (Darodjat dan Wahyudhiana 2014)

Bagi kemajuan masjid PT sebagai pusat keagamaan bisa berprinsip sebagai berikut; Pertama, Keterbukaan sebagai pusat keagamaan Islam hingga tingkatan semua kalangan umat manusia. Optimalisasi semua fungsi sarana penguasaan dan perluasan ragam ilmu bermanfaat bagi kesejahteraan umat secar lahir dan batin. Berbagai sekat yang membatasi secara sosial maupun keagamaan perlu dihindari agar prinsip keterbukaan menuju kebaikan duniawi ukhrowi itu memberikan nilai tersendiri dalam perwujudan persaudaraan dan kesatuan (Hidayat 2014).

Prisip keterbukaan juga perlu diejawantahkan dalam tata lingkungan masjid kampus yang bisa merespon segala kegiatan imani, ibadah, sosial dan ilmiah. keramahan lingkungan, kemudahan akses dengan kelengkapan fasilitas yang memadai bagi pengunjung dan jamaah termasuk para difabel. Pada setiap khutbah Jumat, dan pengajian dapat menampilkan khutbah atau pengajian multibahasa, yaitu bahasa Arab, bahasa Indonesia, bahasa daerah dan bahasa isyarat (Basri dan Dwiningrum 2018).

Kedua, kesesuaian. Orientasi masjid PT harus memelihara asas Islam yang sesuai dengan perkembangan masyarakatnya. Pemaknaannya bisa dilihat dari sisi bentuk dan kawasan yang peduli lingkungan hidup, berhemat daya energi, dan memperhatikan kenyamanan jamaah pengunjung. (Mariyam 2017).

Keempat, masyarakat madani berupa proses memajukan adab budaya umat Islam dalam berbagai aspek kehidupan manusia. Masjid telah mendukung persatuan dan kesatuan semua pihak dalam teritorial Negara Kesatuan Republik Indonesia (NKRI). Tarikh Islam telah memberikan petunjuk yang luas tentang kenyataan masjid sebagai poros penggerak dalam 
pembangunan keunggulan Islam yang bermakna bagi kemanusiaan yang berdimensi masyarakat madani.

\section{Masjid Kampus Wahana Konseling Sebaya berkebangsaan}

Sebagai salah satu ruang public terbuka dalam PT dimana para mahasiswa bisa berkumpul, berdiskusi atau beraktifitas tentang apa saja (Tahir, Cangar, dan Syam 2014), masjid kampus bisa dikembangkan sebagai fasilitator bagi konseling sebaya antar mahasiswa yang menyebarkan agama Islam berkebangsaan anti kekerasan.

Konseling sebaya atau peer counselor secara umum dapat diartikan dengan bimbingan teman sebaya (Akhmadi n.d.). Bimbingan yang diberikan oleh mereka yang berada dalam satu kelompok usia.

Konseling teman sebaya secara kuat menempatkan keterampilan-keterampilan komunikasi untuk memfasilitasi eksplorasi diri dan pembuatan keputusan. Konselor sebaya bukanlah konselor profesional atau ahli terapi. Konselor sebaya adalah para siswa (remaja) yang memberikan bantuan kepada remaja lain di bawah bimbingan konselor ahli (Akhmadi n.d.).

Pola demikan beberapa orang juga mengenalnya sebagai tutor, fasilitator, atau konselor yunior. Bahkan sebagian lainnya lebih cenderung menggunakan istilah dukungan teman sebaya (peer support) (Bashori 2013). Sifatnya lebih umum dan ramah keakraban yang jauh dari kesan formal dan kaku. Pendekatan non-struktural yang mengedepankan dukungan informal berupa saran motivasi dan dorongan. Hubungannya interpersonal dari pribadi teman non-profesional yang berupaya membantu orang lain yang seusia (Putro 2013).

Meski demikian perlu pendampingan dan pelatihan psikologis yang disengaja dan sistematik. Konseling sebaya memungkinkan remaja untuk memiliki keterampilan-keterampilan guna mengimplementasikan pengalaman kemandirian dan kemampuan mengontrol diri yang sangat bermakna bagi remaja. Secara khusus peer counselor tidak memfokuskan pada evaluasi isi, namun lebih memfokuskan pada proses berfikir, proses-proses perasaan dan proses pengambilan keputusan. Dengan cara yang demikian, konseling sebaya memberikan kontribusi pada dimilikinya pengalaman yang kuat yang 
dibutuhkan oleh para remaja yaitu respect.

Bimbingan sebaya terasa penting karena sebagian besar remaja lebih sering membicarakan masalah-masalah mereka dengan teman sebaya dibandingkan dengan orang dewasa dekatnya. Konsul dari mereka yang seusia itu bisa memberikan pandangan yang berbeda dari wawasan orang dewasa sehingga memberikan dampak yang berbeda. Tutor sebaya bisa mengurangi tingkat stress dalam menghadapi perkuliahan (Dini dan Iswanto 2018) sehinngga bisa meningkatkan prestasi akademik (Nugraha, Arifin, dan Saepulrohim 2019). Dalam dampak gaya hidup hedonis, tutor sebaya juga bisa berperan aktif dalam mengatasinya (Jannah dan Sylvia 2018)

Penerapannya kemudian kemudian lebih cenderung dalam pendekatan preventif. Tujuannya pemenuhan kebutuhan untuk memperkuat sebaya dalam menghadapi berbagai pengaruh yang membahayakan, sekaligus mengurangi kejadian dari faktor-faktor destruktif secara psikologis yang terjadi dalam lingkungan.

Ada beberapa hal yang dapat dipertimbangkan demi pribadi mahasiswa yang mampu memberikan peran positif kelompok sebayanya. Ia bisa mendorong ke arah kebaikan dan perdamaian lingkungannya dan menahan diri terlibat dalam kekerasan melakukan beberapa perlakuan (Hanurawan 2013). prinsip keteladanan bagi pribadi yang mengalami kegagalan mencapai identitas peran dan lemahnya kontrol diri pada diri mahasiswa bisa dicegah atau diatasi. Mahasiswa harus bisa mendapatkan sebanyak mungkin figur teman sebaya dan orang-orang dewasa yang telah melampaui masa mahasiswanya dengan baik, dan juga mereka yang berhasil memperbaiki diri.

Dukungan motivasi dari keluarga, dosen, teman sebaya yang mendorong mahasiswa aktif dan lingkugan dan figur sebaya maupun dewasa yang baik serta arahan dengan siapa dan di komunitas mana mahasiswa harus bersosialisasi. Pembekalan ilmu yang bermakna yang terkandung dalam pengetahuan dengan memanfaatkan semua perkembangan sarana dan teknologi termasuk film-film yang bernuansa moral. Lainnya, pembentukan suasana keluarga, sekolah, tempat ibadah, dan organisasi mahasiswa yang 
kondusif, nyaman buat mahasiswa agar dapat berkembang sesuai dengan tahap perkembangan mereka.

Masjid kampus yang memfasilitasi jamaah mahasiswanya sebagai konselor sebaya memiliki posisi istimewa di kalangan masyarakat maupun teman yang bermasalah. Secara lebih spesifik, (Djubaedi 2013) menyimpulkan keunggulannya terutama dalam bimbingan sebaya dalam membina kedamaian dan kerukunan beragama dalam lingkup kebangsaan antara lain; fisik masih kuat, lincah, dan enerjik sehingga dinamis dan kreatif dalam melakukan langkah; Idealisme tinggi, mengikuti apa seharusnya dan tidak menyerah pada keadaan; Independen, orientasi politik belum segmented; cenderung pada solidaritas dibanding ego-sektoral; "Dosanya masih sedikit," track record-nya baik, sedikit atau bahkan tidak mengalami sejarah konflik.

Dengan keistimewaan tersebut, masjid kampus bisa menjadi dinamisator dan pembawa kerukunan dan perdamaian bagi lingkungannya. Pengembangan strategi tutor sebaya dalam masjid kampus bagian dari mengurangi kekerasan dan mengembangkan sikap kebangsaan melalui hubungan kelompok sebayanya.

\section{Penutup}

Masjid kampus sebagai pusat agama berkebangsaan yang anti kekerasan berpotensi sangat besar. Salah satunya dengan pengembangan konseling sebaya dalam masjid kampus. Hal penting lain dalam pengembangan konseling sebaya adalah ragam kemampuan berkaitan dengan partisipasi dan keterlibatan yang dapat dikuasai oleh mereka yang bukan berkeahlian termasuk jamaah mahasiswa. Pelatihan termasuk satu kegiatan perlakuan untuk para mahasiswa tutor sebaya dalam membantu permasalahan psikis dari para teman, terutama yang mengalami permasalahan agama berkebangsaan.

\section{Daftar Pustaka}

Akhmadi, Agus. n.d. "Konseling Sebaya Dalam Bimbingan Konseling Komprehensif." 1-13.

Alfin, Miftachul, dan Fattah Setiawan Santoso. 2013. "Strategi Pengembangan Perguruan Tinggi Agama Islam Sebagai Organisasi Pembelajaran." Ulumuddin $\square$ : Jurnal Ilmu-ilmu Keislaman 3(2):54-67. 
Atika, Thira Sandra, Heri Sunaryanto, dan Sumarto Widiono. 2016. "'Runtuhnya' Masjid Kampus (Studi Gerakan Sosial Politik Masjid Kampus di Bengkulu)." Jurnal Sosiologi Nusantara 2(2):44-57. doi: 10.33369/jsn.2.2.44-57.

Bashori, Khoiruddin. 2013. "Problematika Dan Tantangan Remaja Kontemporer." in Pengembangan Peer Counsellor berbasis Keagamaan sebagai Antisipasi Kekerasan dan Kenakalan Remaja. Yogyakarta.

Basri, Basri, dan Nawang Retno Dwiningrum. 2018. "Potensi Radikalisme di Perguruan Tinggi (Studi Kasus di Politeknik Negeri Balikpapan)." JSHP $\square$ : Jurnal Sosial Humaniora dan Pendidikan 3(1):84-91. doi: 10.32487/jshp.v3i1.546.

Darodjat, dan Wahyudhiana. 2014. "Memfungsikan Masjid Sebagai Pusat Pendidikan Untuk Membentuk Peradaban Islam." Islamadina: Jurnal Pemikiran Islam 13(2):1-13. doi: 10.30595/ISLAMADINA.V0I0.1675.

Dini, Putri Rahma, dan Arif Iswanto. 2018. "Hubungan Dukungan Sosial Teman Sebaya Dengan Tingkat Stres Dalam Menyusun Tugas Akhir Pada Mahasiswa Stikes Ngudi Waluyo Ungaran." Jurnal Ilmu Kebidanan dan Kesehatan 10(2).

Djubaedi, Dedi. 2013. "Peran Sentral Remaja dan Pemuda dalam Membangun Masyarakat Dinamis Harmonis," Makalah dalam pada 3-5 Desember 2013 di Yogyakarta." in Pengembangan Peer Counsellor berbasis Keagamaan sebagai Antisipasi Kekerasan dan Kenakalan Remaja. Yogyakarta.

Hanurawan, Fattah. 2013. Pengembangan Program Pendidikan Pelatihan Perilaku Anti Tawuran Pelajar Berbasis Sikap. Malang.

Hasan, Noorhaidi, ed. 2018. Literatur Keislaman Generasi Milenial Transmisi, Apropriasi, dan Kontestasi. Yogyakarta: Pascasarjana UIN Sunan Kalijaga Press.

Hidayat, Arif. 2014. "Masjid Dalam Menyikapi Peradaban Baru." IBDA: Jurnal Kajian Islam dan Budaya 12(1):13-26. doi: 10.24090/ ibda.v12i1.432.

Huda, Ulul, Tenang Haryanto, dan Budiman Setyo Haryanto. 2018. "Strategi Penanggulangan Radikalisme di Perguruan Tinggi Kabupaten Banyumas." Prosiding Seminar Nasional dan Call for Paper Pengembangan Sumber Daya Pedesaan dan Kearifan Lokal Berkelanjutan VIII, 14-15 November 2018 541-52.

Imroatun, Imroatun. 2015. "Masjid dan Pengembangan Wawasan Anak Usia Dini dalam Pelestarian Lingkungan Hidup Nasional." Ulumuddin: Jurnal Ilmu-ilmu Keislaman 5(1):21-28.

Imroatun, Imroatun. 2016. "Kontribusi Lembaga Pendidikan Agama Islam Dalam Penguatan Identitas Bangsa." Jurnal Ilmiah Bidang pendidikan Studia Didaktika 8(1).

Jannah, Ike Nur, dan Ike Sylvia. 2018. "Hubungan Kelompok Teman Sebaya terhadap Gaya Hidup Hedonisme pada Mahasiswa." Jurnal Perspektif 3(1):187. doi: 10.24036/perspektif.v3i1.199.

Kemenag RI. 2010. Al-Qur'an dan Terjemahnya. Jakarta: Adhi Aksara Abadi.

Mariyam, Siti. 2017. "Masjid Kampus Sebagai Kaderisasi Islami (Prespektif sosiologis terhadap aktifitas masjid Salman ITB dalam berdakwah)."

Nugraha, Desvita, Isep Zaenal Arifin, dan Asep Saepulrohim. 2019. 
"Pengaruh Konseling Teman Sebaya terhadap Peningkatan Hasil Belajar Mahasiswa." Irsyad: Jurnal Bimbingan, Penyuluhan, Konseling, dan Psikoterapi Islam 8(1):19-40. doi: 10.15575/IRSYAD.V8I1.504.

Prastomo, Wiranthi, Muhiyatul Huliyah, M. Nasrudin, Intan Kusumawati, dan AN Ari Bowo. 2019. "Hizbul Wathan Bagi Pendidikan Kemandirian Tingkat Sekolah Dasar." Nuansa Akademik Jurnal Pembangunan Masyarakat 4(1):47-62.

Putro, Khamim Zarkasih. 2013. "Pengaruh Interaksi Antar Teman Sebaya (Peer Group) Terhadap Perilaku Remaja." in Pengembangan Peer Counsellor berbasis Keagamaan sebagai Antisipasi Kekerasan dan Kenakalan Remaja. Yogyakarta.

Qardawi, Yusuf. 2001. As-Sahwah al-Islamiyyah baina al Juhud wa at-Tatarruf. Cairo: Bank at-Taqwa.

Rahayu, Supriati H., Hidayatul Huda, Joko Wahono, Difla Nadjih, dan A. Zain Sarnoto. 2019. "Implementasi Pendidikan Quran Tingkat Lanjut Bagi Santri Usia Dewasa." Nuansa Akademik Jurnal Pembangunan Masyarakat 4(1):63-78.

Rahmat, M. Imdadun. 2011. Ideologi Politik PKS: Dari Masjid Kampus ke Gedung Parlemen. Yogyakarta: LKiS.

Rodin, Dede. 2016. "Islam dan Radikalisme: Telaah atas Ayat-ayat 'Kekerasan' dalam al-Qur'an." ADDIN 10(1):29. doi: 10.21043/addin.v10i1.1128.

Siregar, Edmiraldo. 2018. "Perguruan Tinggi Terpapar Radikalisme - News Liputan6.com." Diambil (https://www.liputan6.com/news/read/ 3549087/perguruan-tinggi-terpapar-radikalisme).

Tahir, Qaharuddin, Hafied Cangar, dan Basir Syam. 2014. Masjid Kampus Sebagai Media Komunikasi Aktivis Dakwah Dalam Pembentukan Karakter Mahasiswa. Vol. 3.

Voll, J. O. 1994. Islam: Continuity and Change in the Modern World. Syracuse: Syracuse University Press. 